\title{
Research on Wargaming for Equipment Support Based On Computer ZHOU Zheng ${ }^{1, a}$, ZHAO Hongyu ${ }^{1, a}$, SHI Xin ${ }^{1, b}$ \\ ${ }^{1}$ Equipment Academy, China \\ azhouzheng82@sina.com, bshixin_1981@126.com
}

Keywords: Mechanization; information, computer wargaming, equipment support training

\begin{abstract}
Computer wargaming for equipment support is to improve the strategy and intelligence level of equipment support commander, and emergency flexibility and strain capacity, can achieve the purpose of setting a better decision. This article elaborates on the computer wargaming, divided into the system platform of basic structure and staff, deduction of the organization process and deduction of the implementation of the three parts explained the implementation of computer wargaming for equipment support, at the end of the computer wargaming for equipment support is prospected.
\end{abstract}

Military base still mechanization, but the core of the current military innovation and change is already information, this is the Chinese army must adapt to the trend of world military revolution. In this not see the smoke of the battlefield, a weak side of war losses may be larger than the mechanical loss. And the future war, fighting for getting a high dependence of equipment support, in order to make it play a better role in the future war, it is particularly necessary for the future war of equipment support training. In the rapid transition to the informationization, produced a computer simulation technology of intelligent, the characteristics of this technology is the man-machine integration, mainly to people, just to meet the need of development of wargame, using this innovative technology to produce computer wargame, it is in the face of the future information war in the highly complex, effective way to achieve scientific decision and accurate assurance of equipment support[1].

\section{Computer wargame}

War is not a new thing. The world accepted the first wargame began in China, "Mo-tse • Gongshu" has found so far the earliest wargame for war analysis and influenced the course of the war of written records. "Sun Zi Bing Fa" is considered the ancestor of the application of wargame principle, so now, wargame history more than 2000 years in our country. The modern wargame recognized originated in seventeenth Century the Prussian army, now has 200 years of history. With the development of industrial civilization and Prussian (Germany) the rapid rise of the army, wargame get promotion and popularization.

With the programming technology and artificial intelligence technology in the development of late 80's in the last century, rapidly improve technology of computer wargame developed western countries, especially American, and become the mainstream form of modern wargame. Computer wargame makes use of information, the use of programming technique; make manual wargame into computer wargame, and through the form of computer software performance. To compare the two, does not have the essential difference, only the display form and Adjudication of different. Computer wargame, showing the six angle map grid and situation map screen, instead of manual wargame six angle board with effect diagram; 2D display of weapons and troops, instead of manual wargame pieces; computer decision system, instead of manual of wargames adjudication, including artificial look-up table, dice take random numbers. Although manual wargame and computer wargame is basically the same, but the computer wargame remedies the defects of manual wargame, simplified look-up table, calculate and record the work, and added a new function, training more diverse forms. More and more computer wargame in function close to the battlefield, has the very strong fidelity, including the use of a display of 2D map and battlefield situation, real-time reporting of battle damage, 
the entire record and playback deduction process and other functions, through the grouping resistance, man-machine deduction and remote network against the other group training form, make the preview of war, for war equipment support training to become possible, and scientific accuracy is higher, can give full play to the wisdom of the commanders[2].

\section{The computer wargaming system in the organization and implementation of equipment support training.}

The basic structure of the system platform. This computer wargaming system platform is convenient, simple operation, due to the use of the browser-server structure, the basic will not appear crash phenomenon, make the deduction can be smoothly carried out, need not worry to be interference and interruption, and can reduce the maintenance workload of the client. Figure 1 shows the basic structure of the platform[3].

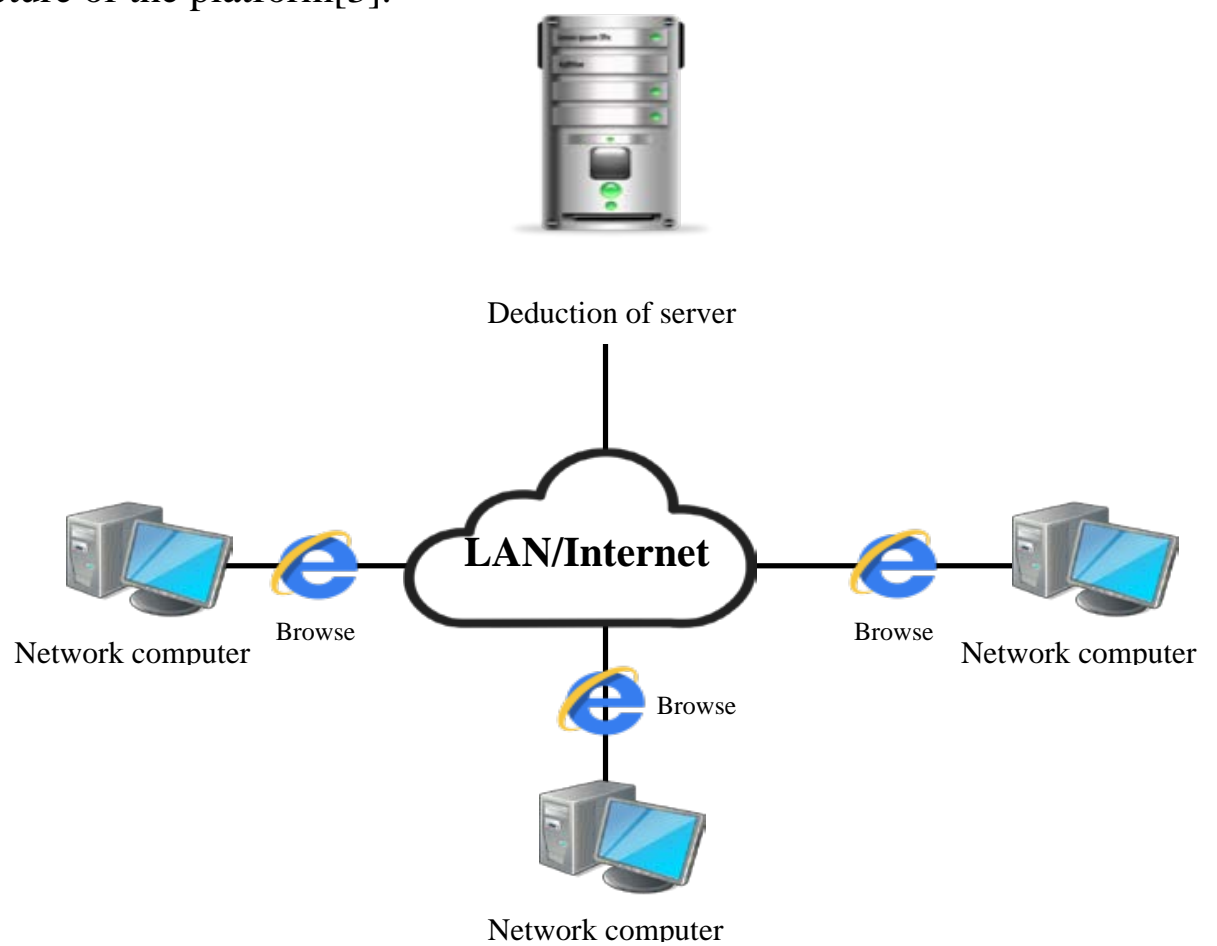

Fig. 1 the basic structure of the platform

The Deduction of personnel. Computer wargaming system for equipment support training, can carry out various forms of training, staff can use the system platform individually deduction, can also through the network form organization staff deduction. The main staff including: 1 the director department, the staff design deduction scenario and control the whole process; 2 both red and blue, participate in the deduction of the staff, including commander of equipment support, system function of users; 3 experts, by observing may at any time to the guidance of the deduction; 4 administrator, maintenance system.

The computer wargaming system in the implementation of equipment support training.The computer wargaming system for equipment support training refers to the set of equipment support task specific operations of the expected, transport supply, battlefield repair and other aspects of the drill. Figure 2 shows the deduction process. 


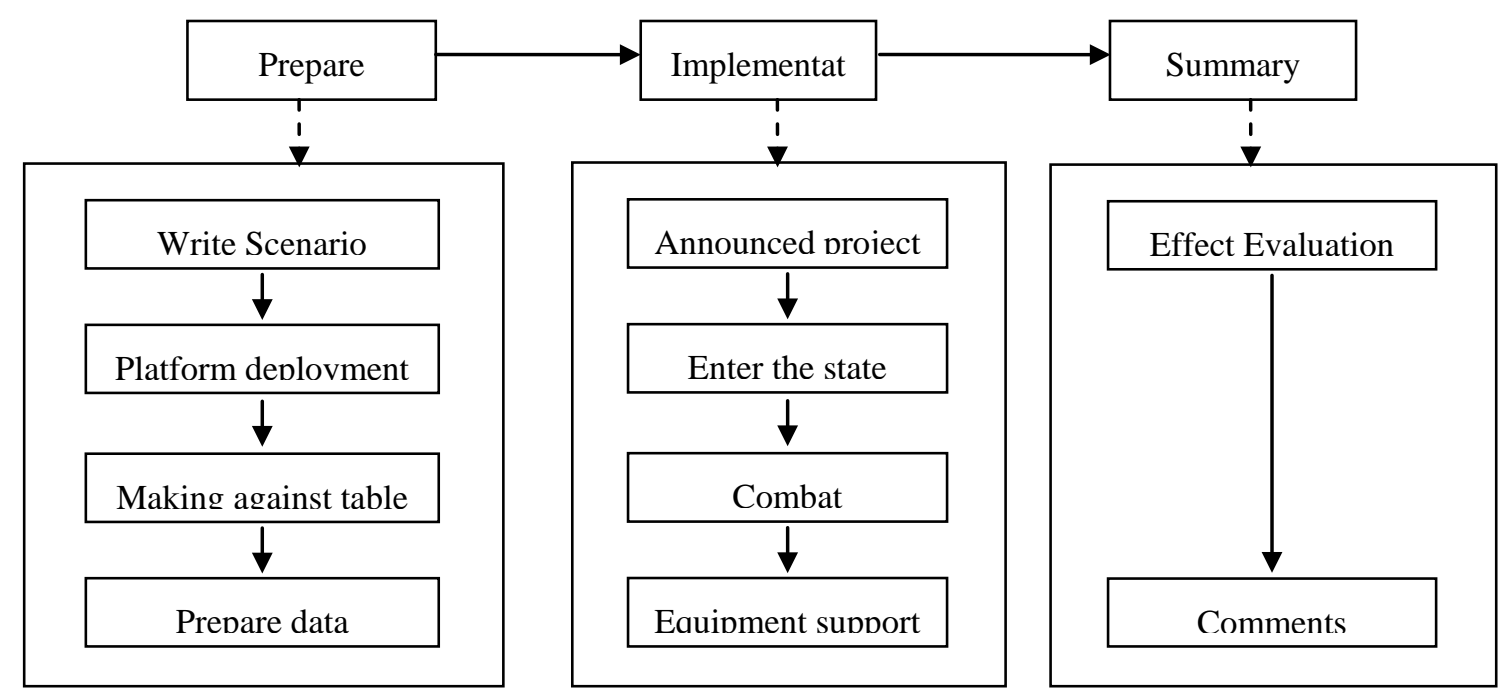

Fig. 2 the deduction process

\section{Prospect of application of computer wargaming for equipment support training}

As a kind of near the battlefield training tool, wargame plays an important role in learning, research and exercise to set decision, because it is based on the historical experience of war, the rules and calculation are concise and simplified, highlighting the commander will make up your mind. Therefore, with other forms of combat simulation compared, wargame can not be replaced. The training is introduced to computer wargame for equipment support, this innovative training methods, it will have a positive impact on equipment support research and training[4].

The equipment support training for war, so that now the training close to tomorrow's war.To ensure that the equipment support in the war is more reasonable and efficient, then go to the training in accordance with the guarantee mechanism of information war. Just like in the deduction, the enemy suddenly attack our important equipment in our key nodes, enable us to lose command decision-making ability, if the commander cannot accurate equipment support command and decision-making, timely recovery of function, in this time period, the enemy will be precision strike and paralyze our combat system, enable us to completely fall into a passive situation of being beaten. Through the computer wargaming system for equipment support training, such as accurate, efficient concept will be strengthened in the mind of the commander. Especially in computing, digital and data concept left a deep impression on the commander thought. This will let the commander pay more attention to accurate, precise and exercise equipment support ability of strategic thinking.

Increased training equipment support command talents means for future war. Future warfare is information warfare, digital, intelligent, information of weapons and equipment, so that the war has become intelligent and information of the contest. Because the training cycle is long, the weapons and equipment updates faster, the influence of knowledge aging quick speed variation and other factors, makes the talent training of equipment support command is difficult to meet the demand for war [4]. Computer wargaming height close to the war, increased training of equipment command talents means, and wargaming changes like the battlefield situation vary from minute to minute, created such a realistic environment. The use of computer wargaming system for equipment support training exercises, with the practice of equipment support commander. Let the doctors and masters of these highly educated talents, to participate in the wargaming, the formation of a red and blue, using the real ideological battle, combat principle, operational organization and equipment of confrontation, exercise equipment support, both to the opponent to set all kinds of difficulties, crisis and dangers, forcing the other equipment support commander at the most difficult in the game of "count", "seeking", "defend", truly cultivate talents of equipment support command for war.

Help change the equipment support commander mind-set and command mode. Computer wargaming is applied to equipment support domain, so that the equipment support commander true perception of battlefield situation, simulated battlefield equipment loss, supplies and equipment as 
well as terrain, climate and other natural factors on various related factors affecting equipment support etc., and taking a random number, embodies the war uncertainty and contingency, the approximation the battle of temper. Against both commanders in this state, the equipment support, are to be considered is no longer on a damaged target simple security, but like a chess game, the next step even to consider the next ten step. The fog of war number showed a deduction, uncertainty and contingency system using random access, in the deduction process, will completely change the mind-set and command mode commander inherent, let the commander always keenly aware of the existence of a strong opponent, always strongly feel there is a real the operational pressure, always have deep experience to watch a step would lead to the failure of force commander to put forward the strategy and method to deal with the. It plays an irreplaceable role in improving commander own military accomplishment, ability of decision-making and command capability.

\section{Conclusion}

In the practice of strengthening the military targets, and strive to achieve the great journey of dream army, training must be future oriented equipment support commander of the war. The use of computer wargaming in equipment support domain still need further study, but it can dig potential is very great, in the face of war information in the future, make it become an important platform for battlefield training, and to exercise a victorious war army contribution to a force.

\section{References}

[1]YAN Nanzheng. Wargame, War Game, Simulation [M]. Beijing: PLA press, 2007:15-25.

[2]LI Jiaxiang, Wu Qin, LI Yueping. Analysis of wargaming [J].Chang Ying: 2010(8):22-23.

[3]HAN Zhijun, LIU Shaojun, TANG Ningbo, JING Min. Research on computer wargaming system [J].Computer Simulation:2011(4):10-13.

[4]Y. Mishing, in: Diffusion Processes in Advanced Technological Materials, edtied by D. Gupta Noyes Publications/William Andrew Publising, Norwich, NY (2004), in press.

[5]HE Jianping, ZHAN Leilei. Research on the weapon of war: wargame [J]. Silicon valley: 2009:216.Reference 